\title{
IGFBP-3 A-202C and C2133G polymorphisms and colorectal cancer risk: a meta-analysis of case-control studies
}

\author{
J. Xu' ${ }^{1}$, L. Xu' ${ }^{2}$, L.T. Li ${ }^{1}$, Q. You ${ }^{1}$ and L.S. Cha ${ }^{1}$ \\ 'Department of General Surgery, Changzheng Hospital, \\ Second Military Medical University, Shanghai, China \\ ${ }^{2}$ Department of Vascular Surgery, Changzheng Hospital, \\ Second Military Medical University, Shanghai, China \\ Corresponding author: J. Xu \\ E-mail: czyy_xj@126.com
}

Genet. Mol. Res. 14 (2): 3370-3386 (2015)

Received June 12, 2013

Accepted October 1, 2014

Published April 15, 2015

DOI http://dx.doi.org/10.4238/2015.April.15.1

\begin{abstract}
Recent evidence suggests that genetic variations in the IGFBP-3 gene may impact susceptibility to colorectal cancer, but individually published results are inconclusive. Our meta-analysis was aimed at providing a more precise estimation of these associations. An extensive literature search was conducted for appropriate articles published before May 1, 2013. This meta-analysis was performed using the STATA 12.0 software. The crude odds ratios (OR) with 95\% confidence interval (CI) were calculated. Eleven case-control studies were included with a total of 11,895 colorectal cancer patients and 17,147 healthy controls. Our meta-analysis indicated that the $\mathrm{G}$ variant of IGFBP-3 C2133G polymorphism may be associated with increased colorectal cancer risk. However, no statistically significant association was noted between IGFBP-3 A-202C polymorphism and colorectal cancer risk. No publication bias was detected in this metaanalysis. The current meta-analysis suggests that the IGFBP-3 C2133G polymorphism may confer susceptibility to colorectal cancer. The G
\end{abstract}


variant of the IGFBP-3 C2133G polymorphism may serve as a useful biomarker for predicting the risk of colorectal cancer.

Key words: Colorectal cancer; Polymorphism; IGFBP-3; Meta-analysis; Meta-regression

\section{INTRODUCTION}

Colorectal cancer is the third most commonly diagnosed cancer in men and the second in women, with over 1.2 million new cancer cases and 608,700 deaths estimated to have occurred in 2008 (Jemal et al., 2011). Colorectal cancer is a multifactorial disease caused by complex interactions between environmental and genetic factors (de la Chapelle, 2004). However, the exact cellular and molecular mechanisms leading to the development of colorectal cancer remain unclear. Nowadays, a large number of candidate genes responsible for the genesis of colorectal cancer have been identified (Markowitz and Bertagnolli, 2009). Determination of single-nucleotide polymorphisms (SNPs) in candidate genes may prove to be reliable in predicting the genetic risk of colorectal cancer and might thus contribute to the primary prevention of this condition (Chan and Giovannucci, 2010).

Insulin-like growth factors (IGFs) are major determinants of proliferation and apoptosis and thus may influence carcinogenesis (Giovannucci, 2001). The vast majority of circulating IGFI is bound to IGF-binding proteins (IGFBPs), predominantly IGFBP-3 in complex with an acidlabile subunit, which restrict the bioactive IGFs and limit their interaction with receptors (Kim et al., 2011). Emerging interest in IGFBP-3 and its effect on carcinogenesis has increased because low serum levels of IGFBP-3 has been associated with increased risk of various human cancers, including colorectal cancer (Furstenberger and Senn, 2002). Therefore, it was hypothesized that variations in the IGFBP-3 gene might be associated with colorectal cancer risk.

The Human IGFBP-3 gene is located on the chromosome 7p13-p12. This gene is a member of the IGFBP family and encodes a protein with an IGFBP domain and a thyroglobulin type-I domain (Kaplan et al., 2011). Several SNPs have been identified in the IGFBP-3 gene. Among these SNPs, A-202C (rs2854744) and C2133G (rs2854746) are the most common and widely investigated polymorphisms (Ren et al., 2004; Le Marchand et al., 2005). The A-202C, an SNP in the promoter region of the IGFBP-3 gene, results from an A to C nucleotide change at the position -202 and is a highly functional polymorphism (Costalonga et al., 2009). The $\mathrm{C} 2133 \mathrm{G}$ is a missense substitution of $\mathrm{C}$ to $\mathrm{G}$ in the exon 1 (Le Marchand et al., 2005). Recent evidence has suggested that common polymorphisms in the IGFBP-3 gene may be associated with increased colorectal cancer risk; however, individually published results are inconclusive. Therefore, we attempt to perform a meta-analysis of all eligible case-control studies to provide insights into these associations, which may promote our understanding of the exact role of IGFBP-3 in the development of colorectal carcinogenesis.

\section{MATERIAL AND METHODS}

\section{Search strategy and selection criteria}

An extensive literature search for relevant studies was conducted on Pubmed, 
Embase, Web of Science, Cochrane Library, and CBM databases from inception through May 1, 2013. We used the following key words and MeSH terms: ('genetic polymorphism' or 'single nucleotide polymorphism' or 'polymorphism' or 'SNP' or 'mutation' or 'variation' or 'variant') and ('colorectal cancer' or 'CRC' or 'colon cancer' or 'rectal cancer') and ('insulin-like growth factor binding protein 3' or 'IGFBP-3' or 'IGF binding protein 3'). There was no language restriction. Manual search of reference lists from potentially relevant articles was performed to identify other potential studies. To be included in the analysis, these studies must meet the following criteria: 1) Case-control studies focus on the associations between IGFBP-3 A-202C and C2133G polymorphisms and colorectal cancer risk; 2) All patients diagnosed with colorectal cancer are confirmed by histopathologic examinations; 3) Published data about genotype frequencies of SNPs is sufficient; 4) Genotype distribution in healthy controls should conform to the Hardy-Weinberg equilibrium (HWE). Studies were excluded if they do not meet all of these inclusion criteria. Any disagreements were resolved by discussions and subsequent consensus.

\section{Data extraction}

Two authors (L. Xu and L.T. Li) independently extracted data from eligible studies by using a standardized form. The following information was collected prospectively: surname of first author, year of publication, source of publication, country of origin, ethnicity, language of publication, study type, total number of subjects, source of cases and controls, pathological type, SNP type, DNA sample, SNP detection method, genotype frequencies, and evidence of HWE in controls. In cases of conflicting evaluations, disagreements on inconsistent data from the eligible studies were resolved through discussion and careful reexamination of the full text by the authors.

\section{Quality assessment}

The quality of included studies was assessed independently by 2 authors (Q. You and L.S. Cha) based on the STREGA quality score systems (Little et al., 2009). Twenty-two assessment items related to quality appraisal were used in this meta-analysis with scores ranging from 0 to 22. The included studies were classified into 3 levels based on their scores: low quality (0-12), moderate quality (13-17), and high quality (18-22), respectively. Disagreements on STREGA scores of the included studies were resolved through a comprehensive reassessment by the authors.

\section{Statistical analysis}

The odds ratios (ORs) and 95\% confidence intervals (CIs) were calculated under 5 genetic models: allele model [mutant (M) allele versus wild (W) allele], dominant model ( $\mathrm{WM}+\mathrm{MM}$ versus $\mathrm{WW})$, recessive model (MM versus $\mathrm{WW}+\mathrm{WM})$, homozygous model (MM versus WW), and heterozygous model (MM versus WM). The significance of the pooled estimate was determined using the $Z$-test. Genotype distributions in the control subjects were tested for conformance to HWE by the chi-square test. We estimated the degree of heterogene- 
ity among studies by using Cochran's $Q$-statistic, which is considered to be significant at $\mathrm{P}<$ 0.05 (Jackson et al., 2012). The $\mathrm{I}^{2}$ test was also used to quantify the heterogeneity (ranges from 0 to $100 \%$ ) (Peters et al., 2006). When a significant $Q$-test with $\mathrm{P}<0.05$ or $\mathrm{I}^{2}>50 \%$ indicated that heterogeneity among studies existed, the random-effect model (DerSimonian Laird method) was conducted for the meta-analysis; otherwise, the fixed-effect model (Mantel-Haenszel method) was used. In order to explore sources of heterogeneity, subgroup analyses were performed based on ethnicity, gene type, source of control, and SNP detection method. Univariate and multivariable regression analyses were also performed to identify potential sources of heterogeneity (Ioannidis et al., 2008). To evaluate the influence of single studies on overall risk estimate, we conducted a sensitivity analysis by omitting each study in turn. Funnel plots and the Egger linear regression test were used to assess potential publication bias of included studies (Zintzaras and Ioannidis, 2005). All tests were two-sided and a P value of $<0.05$ was considered to be statistically significant. All analyses were calculated using the STATA software, version 12.0 (Stata Corp., College Station, TX, USA).

\section{RESULTS}

\section{Baseline characteristics of included studies}

A total of 145 articles relevant to the searched key words were initially identified. Of these articles, 66 were excluded after reviewing their titles and key words; then, abstract and full text were reviewed, and another 68 papers were excluded. Eleven case-control studies met our inclusion criteria (Le Marchand et al., 2005; Morimoto et al., 2005; Wong et al., 2005; Samowitz et al., 2006; Slattery et al., 2004, 2006; Pechlivanis et al., 2007; Xiang et al., 2009; Feik et al., 2010; Keku et al., 2012; Ollberding et al., 2012). The publication years of the involved studies ranged from 2004 to 2012. A flow chart of the selection procedures is shown in Figure 1. A total of 29,042 subjects were involved in this meta-analysis, including 11,895 colorectal cancer patients and 17,147 healthy controls. Three studies used hospital-based controls, while the other 8 studies used populationbased controls (community populations). Eight studies were conducted in Caucasian populations, 2 in Asian populations, and 1 in African populations. The DNA samples used for examination of genetic polymorphisms were extracted from blood in all included studies. The classical polymerase chain reaction-restriction fragment length polymorphism (PCR-RFLP) method was performed in 5 studies; the other 6 studies used TaqMan assay method. Two common polymorphisms in the IGFBP-3 gene were addressed, including A-202C (rs2854744) and C2133G (rs2854746). The HWE test was conducted on the genotype distribution of the controls in all 11 studies. Each study did not deviate from the HWE (all P >0.05). The characteristics and methodological quality of the included studies are summarized in Table 1.

\section{IGFBP-3 A-202C polymorphism and colorectal cancer risk}

The association between IGFBP-3 A-202C polymorphism and colorectal cancer risk was discussed in nine studies. The heterogeneity is not obvious $(\mathrm{P}>0.05)$, and therefore, the fixed-effect model was used. The meta-analysis results indicated that the IGFBP-3 A-202C 


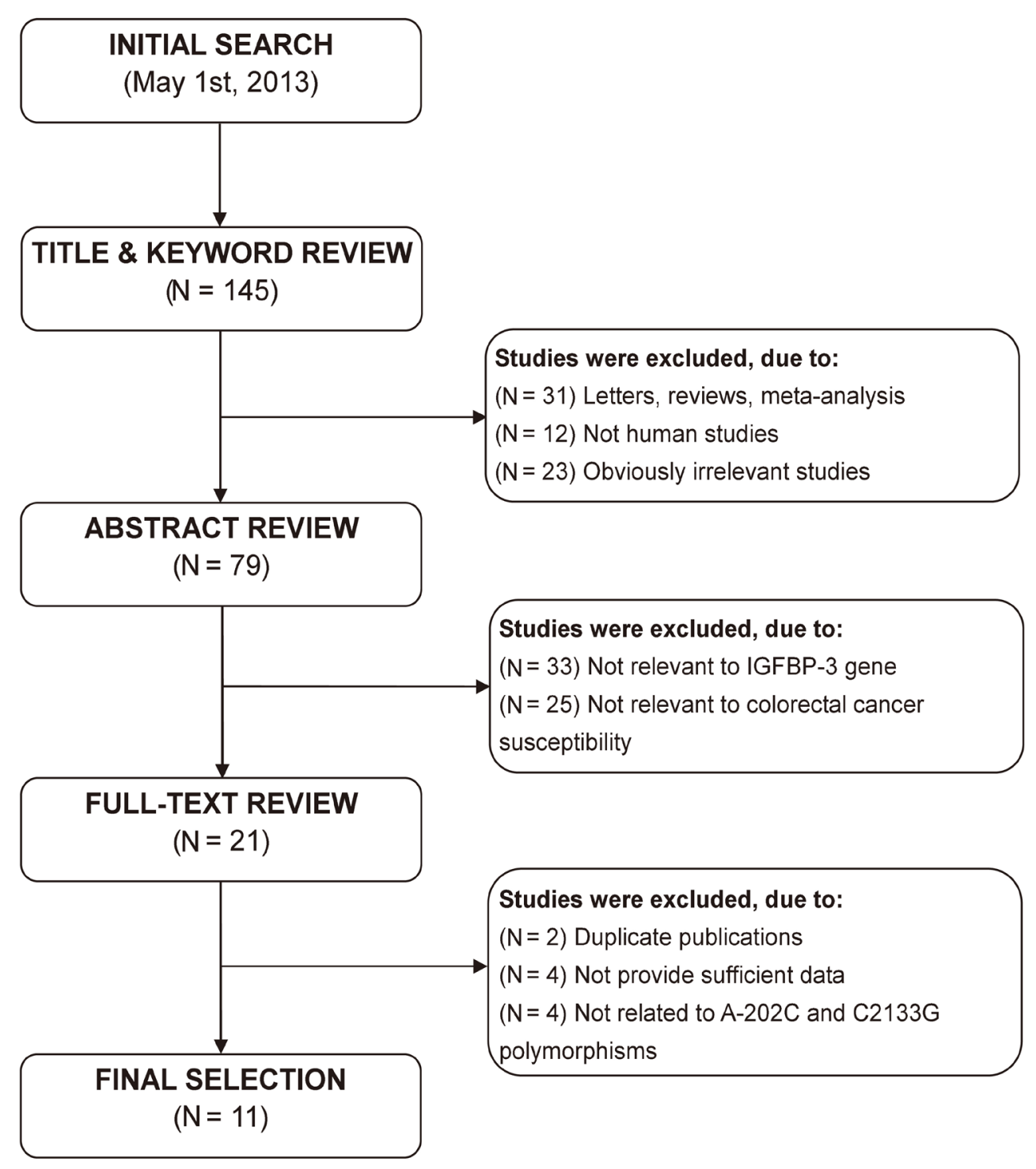

Figure 1. Flow chart of literature search and study selection.

polymorphism may not be associated with colorectal cancer risk $(\mathrm{C}$ allele $v s \mathrm{~A}$ allele: OR $=1.00,95 \% \mathrm{CI}=0.96-1.04, \mathrm{P}=0.936 ; \mathrm{AC}+\mathrm{CC}$ vs $\mathrm{AA}: \mathrm{OR}=1.00,95 \% \mathrm{CI}=0.94-1.06, \mathrm{P}$ $=0.991 ; \mathrm{CC} v s \mathrm{AA}+\mathrm{AC}: \mathrm{OR}=1.01,95 \% \mathrm{CI}=0.94-1.07, \mathrm{P}=0.880 ; \mathrm{CC} v s \mathrm{AA}: \mathrm{OR}=1.01$, $95 \% \mathrm{CI}=0.93-1.09, \mathrm{P}=0.826 ; \mathrm{CC}$ vs $\mathrm{AC}: \mathrm{OR}=1.01,95 \% \mathrm{CI}=0.94-1.08, \mathrm{P}=0.879$ ) (Figure 2). Further subgroup analyses also showed no significant associations between IGFBP-3 A$202 \mathrm{C}$ polymorphism and colorectal cancer risk in any subgroups (as shown in Table 2). 
IGFBP-3 A-202C and C2133G in colorectal cancer risk

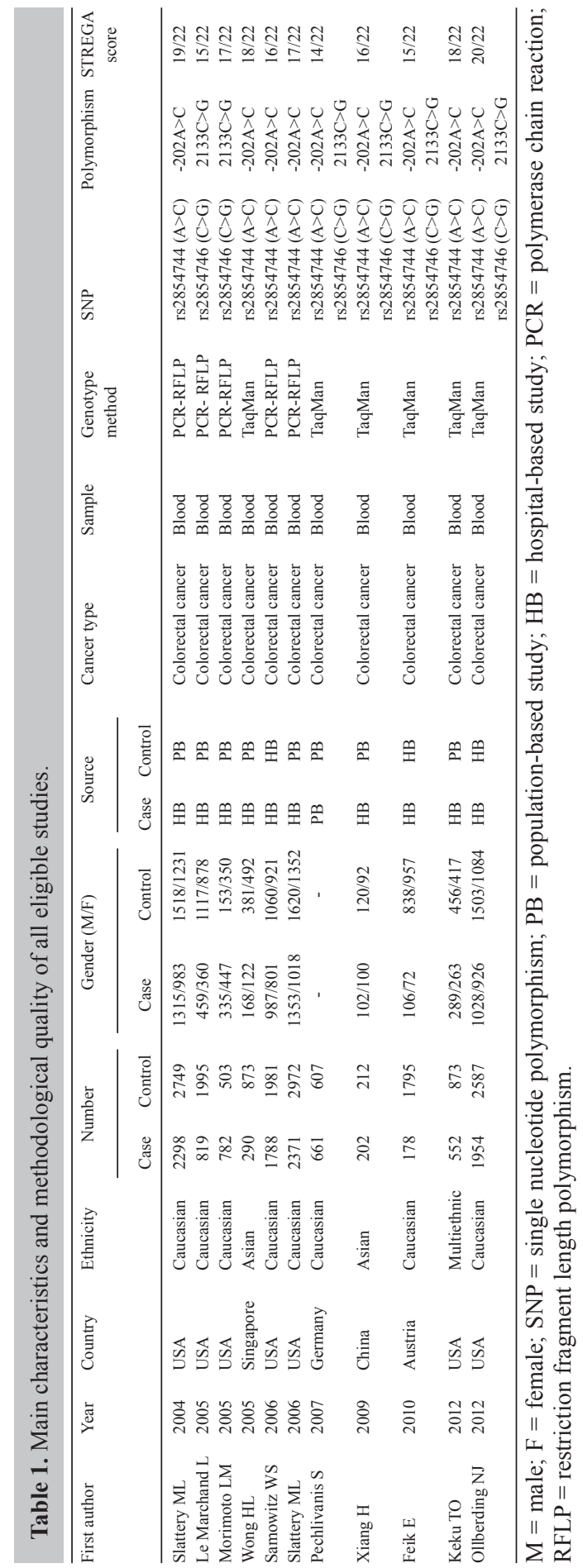




\begin{tabular}{|c|c|c|c|}
\hline Study ID & $\begin{array}{c}\text { Allele model } \\
\text { (C allele versus } A \text { allele) }\end{array}$ & OR $(95 \% \mathrm{Cl})$ & Weight $\%$ \\
\hline Slattery ML (2004) & & $1.03(0.95,1.13)$ & ) 19.02 \\
\hline Wong HL (2005) & & $0.97(0.77,1.23)$ & 2.76 \\
\hline Samowitz WS (2006) & & $0.99(0.90,1.08)$ & ) 17.47 \\
\hline Slattery ML (2006) & & $0.98(0.90,1.05)$ & ) 24.85 \\
\hline Pechlivanis S (2007) & & $0.95(0.81,1.12)$ & 5.62 \\
\hline Xiang H (2009) & & - $1.14(0.82,1.59)$ & 1.26 \\
\hline Feik E (2010) & & $0.95(0.73,1.23)$ & ) 2.19 \\
\hline Keku TO-(African) (2012) & & $1.08(0.89,1.32)$ & 3.59 \\
\hline Keku TO-(Caucasian) (2012) & & $0.94(0.74,1.19)$ & 2.65 \\
\hline Ollberding NJ (2012) & & $1.02(0.94,1.11)$ & 20.59 \\
\hline Overall $\left(R^{2}=0.0 \%, P=0.943\right)$ & & $1.00(0.96,1.04)$ & ) 100.00 \\
\hline 0.63 & 1 & 1.59 & \\
\hline Study ID & $\begin{array}{c}\text { Dominant model } \\
(A C+C C \text { versus } A A)\end{array}$ & OR $(95 \% \mathrm{Cl})$ & Weight $\%$ \\
\hline Slattery ML (2004) & & $1.07(0.93,1.22)$ & 17.53 \\
\hline Wong HL (2005) & & $0.90(0.68,1.19)$ & 4.60 \\
\hline Samowitz WS (2006) & & $1.04(0.90,1.20)$ & ) 16.53 \\
\hline Slattery ML (2006) & - & $0.95(0.85,1.08)$ & 24.36 \\
\hline Pechlivanis S (2007) & & $1.02(0.77,1.34)$ & 4.39 \\
\hline Xiang H (2009) & & $1.15(0.77,1.71)$ & ) 2.02 \\
\hline Feik E (2010) & & $0.93(0.63,1.39)$ & 2.18 \\
\hline Keku TO-(African) (2012) & & $0.98(0.70,1.35)$ & 3.23 \\
\hline Keku TO-(Caucasian) (2012) & & $0.92(0.64,1.30)$ & ) 2.86 \\
\hline Ollberding NJ-1 (2012) & & $0.99(0.88,1.12)$ & 22.30 \\
\hline Overall $\left(R^{2}=0.0 \%, P=0.958\right)$ & & $1.00(0.94,1.06)$ & ) 100.00 \\
\hline
\end{tabular}

Figure 2. Forest plots for the associations between IGFBP-3 A-202C polymorphism and colorectal cancer risk. The squares and horizontal lines correspond to the study-specific OR and $95 \% \mathrm{CI}$. The area of the squares reflects the weight (inverse of the variance). The diamond represents the summary OR and 95\%CI.

\section{IGFBP-3 C2133G polymorphism and colorectal cancer risk}

Six studies referred to the association between IGFBP-3 C2133G polymorphism and colorectal cancer risk. Since heterogeneity obviously existed $(\mathrm{P}<0.05)$, the random-effect 


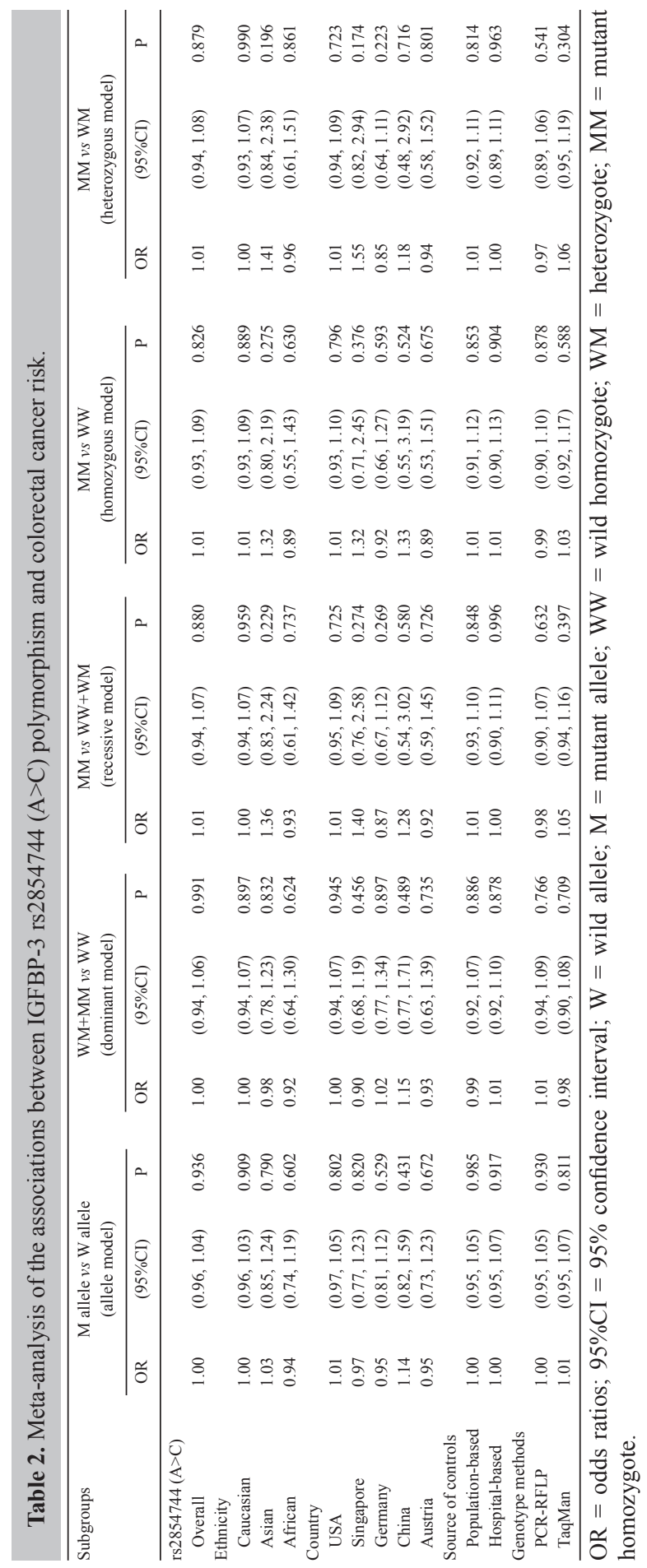


model was conducted. Meta-analysis of these studies showed significant associations between the $\mathrm{G}$ variant of IGFBP-3 $\mathrm{C} 2133 \mathrm{G}$ polymorphism and an increased colorectal cancer risk (G allele $v s \mathrm{C}$ allele: $\mathrm{OR}=1.07,95 \% \mathrm{CI}=1.01-1.15, \mathrm{P}=0.019 ; \mathrm{CG}+\mathrm{GG} v s \mathrm{CC}: \mathrm{OR}=1.19$, $95 \% \mathrm{CI}=1.09-1.29, \mathrm{P}<0.001 ; \mathrm{GG} v s \mathrm{CC}: \mathrm{OR}=1.13,95 \% \mathrm{CI}=1.01-1.25, \mathrm{P}=0.027 ; \mathrm{GG}$ vs CG: $\mathrm{OR}=1.11,95 \% \mathrm{CI}=1.01-1.23, \mathrm{P}=0.035$ ) (Figure 3). We also performed subgroup analyses based on ethnicity, country, source of control, and SNP detection method. Subgroup analysis by ethnicity showed that the G variant of IGFBP-3 C2133G polymorphism may confer to susceptibility to colorectal cancer among both Caucasian and Asian populations (Figure 4). Further subgroup analyses suggested significant associations between IGFBP-3 C2133G polymorphism and colorectal cancer risk in the majority of subgroups (as shown in Table 3). Although no significant association between IGFBP-3 C2133G polymorphism and colorectal cancer risk was found in the Germany, Austria, hospital-based subgroups (all P >0.05), these results might lack sufficient reliability because of the small sample size.

\begin{tabular}{|c|c|c|c|}
\hline Study ID & $\begin{array}{l}\text { Allele model } \\
\text { (G allele versus } C \text { allele) }\end{array}$ & OR $(95 \% \mathrm{Cl})$ & Weight \% \\
\hline Le Marchand L (2005) & $\rightarrow$ & $0.80(0.71,0.90)$ & 26.90 \\
\hline Morimoto LM (2005) & & - $1.72(1.46,2.02)$ & 9.55 \\
\hline Pechlivanis S (2007) & & $1.01(0.86,1.19)$ & 11.83 \\
\hline Xiang $\mathrm{H}$ (2009) & & $1.45(1.06,1.98)$ & 3) 2.71 \\
\hline Feik E (2010) & & $1.01(0.78,1.32)$ & 4.58 \\
\hline Ollberding NJ (2012) & & $1.09(1.00,1.18)$ & 44.43 \\
\hline Overall $\left(l^{2}=92.0 \%, P<0.000\right)$ & & $1.07(1.01,1.13)$ & ) 100.00 \\
\hline 0.496 & 1 & 2.02 & \\
\hline Study ID & $\begin{array}{c}\text { Dominant model } \\
(C G+G G \text { versus } C C)\end{array}$ & OR $(95 \% \mathrm{Cl})$ & Weight \% \\
\hline Le Marchand L (2005) & & $1.07(0.90,1.28)$ & ) 23.80 \\
\hline Morimoto LM (2005) & & $-2.00(1.56,2.56)$ & 8.84 \\
\hline Pechlivanis S (2007) & & $1.14(0.89,1.47)$ & ) 11.75 \\
\hline Xiang $\mathrm{H}$ (2009) & & $1.55(1.05,2.30)$ & 4.14 \\
\hline Feik E (2010) & & $0.97(0.66,1.43)$ & 5.30 \\
\hline Ollberding NJ (2012) & 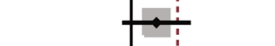 & $1.10(0.97,1.25)$ & ) 46.16 \\
\hline Overall $\left(P^{2}=77.8 \%, P<0.000\right)$ & & $1.19(1.09,1.29)$ & 100.00 \\
\hline
\end{tabular}

Figure 3. Forest plots for the associations between IGFBP-3 C2133G polymorphism and colorectal cancer risk. The squares and horizontal lines correspond to the study-specific OR and $95 \% \mathrm{CI}$. The area of the squares reflects the weight (inverse of the variance). The diamond represents the summary OR and 95\%CI. 


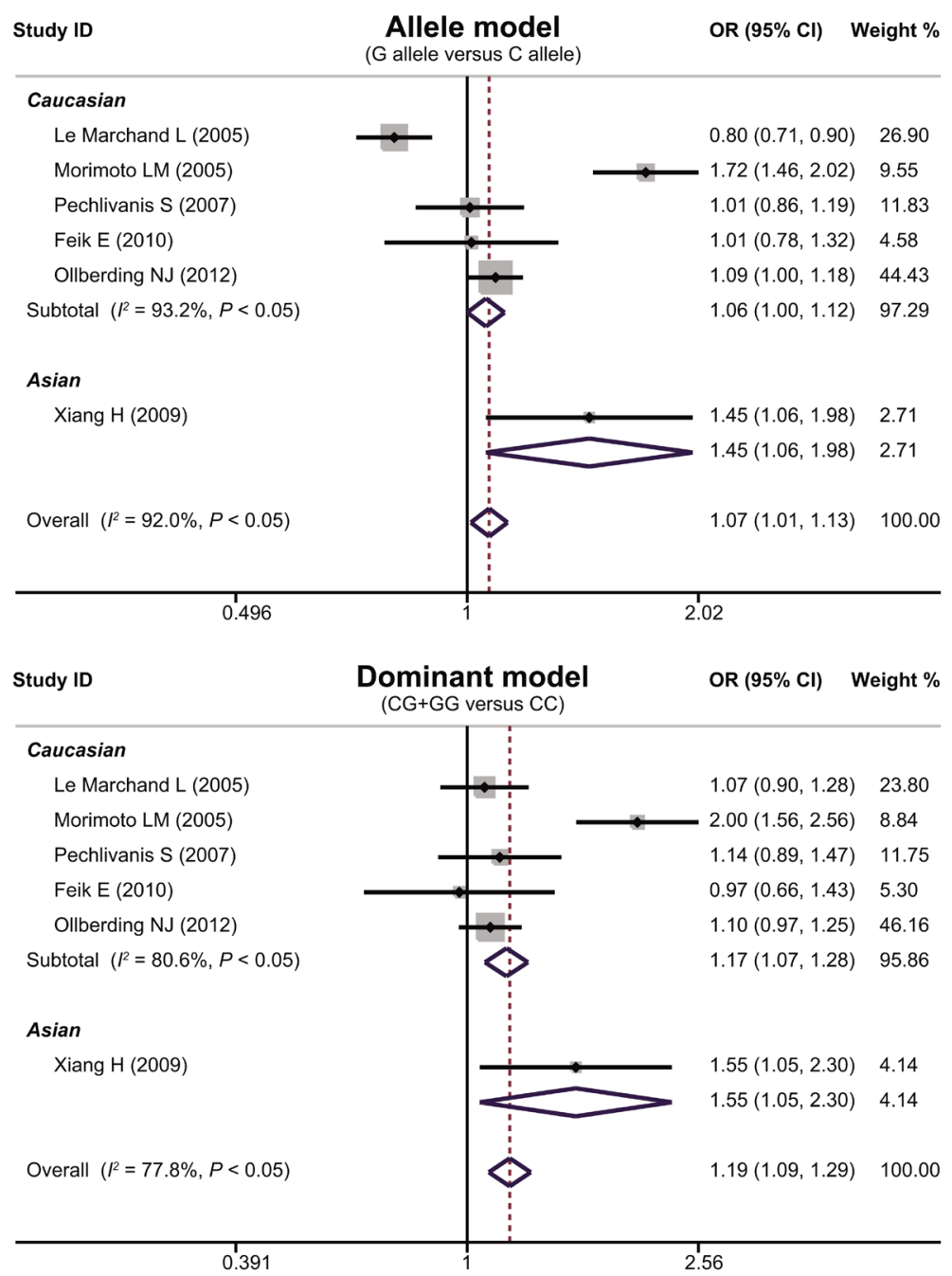

Figure 4. Subgroup analysis by ethnicity for the associations between IGFBP-3 C2133G polymorphism and colorectal cancer risk. The squares and horizontal lines correspond to the study-specific OR and 95\%CI. The area of the squares reflects the weight (inverse of the variance). The diamond represents the summary OR and $95 \% \mathrm{CI}$.

\section{Meta-regression and sensitivity analyses}

Univariate and multivariate meta-regression analyses were conducted for A-202C and $\mathrm{C} 2133 \mathrm{G}$ polymorphisms. The results showed that none of potential factors may explain the sources of heterogeneity (as shown in Table 4). Sensitivity analysis was performed to assess the influence of each individual study on the pooled OR by omitting each individual studies in turn. The results suggested that no individual studies significantly affected the pooled ORs under the dominant model of A-202C and C2133G polymorphisms (Figure 5). 


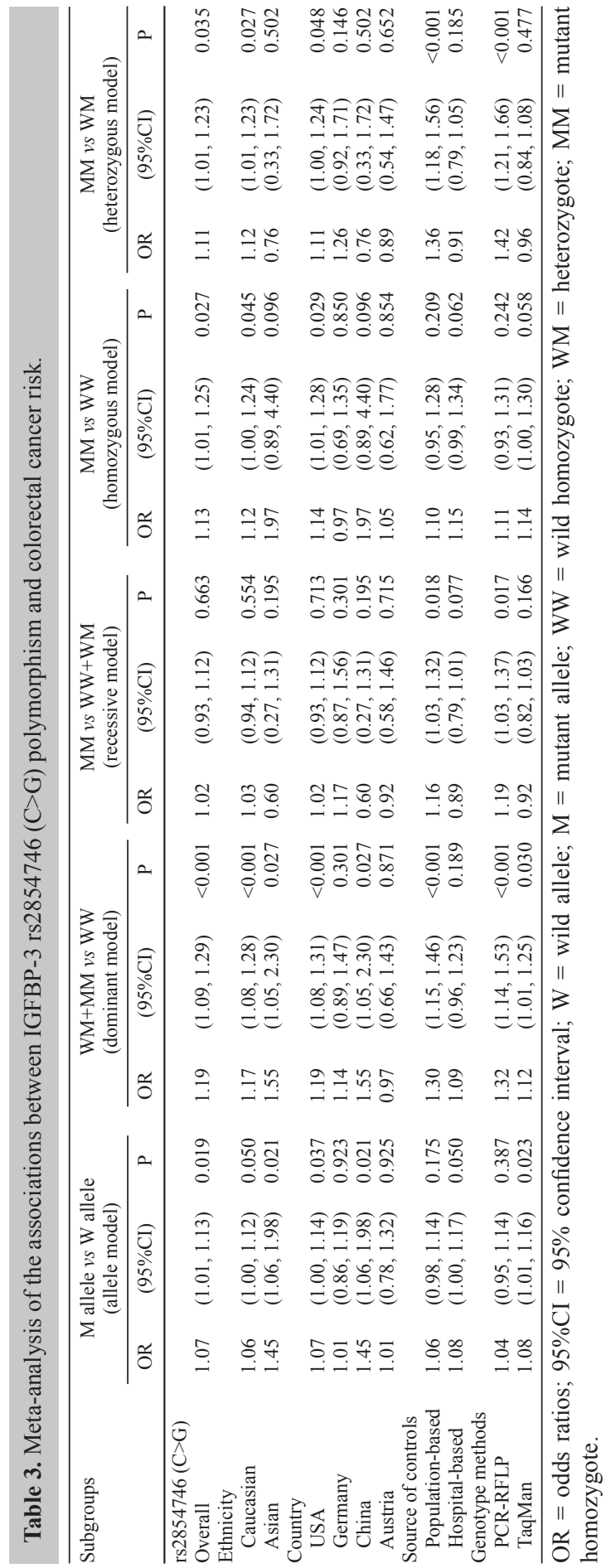


IGFBP-3 A-202C and C2133G in colorectal cancer risk

3381

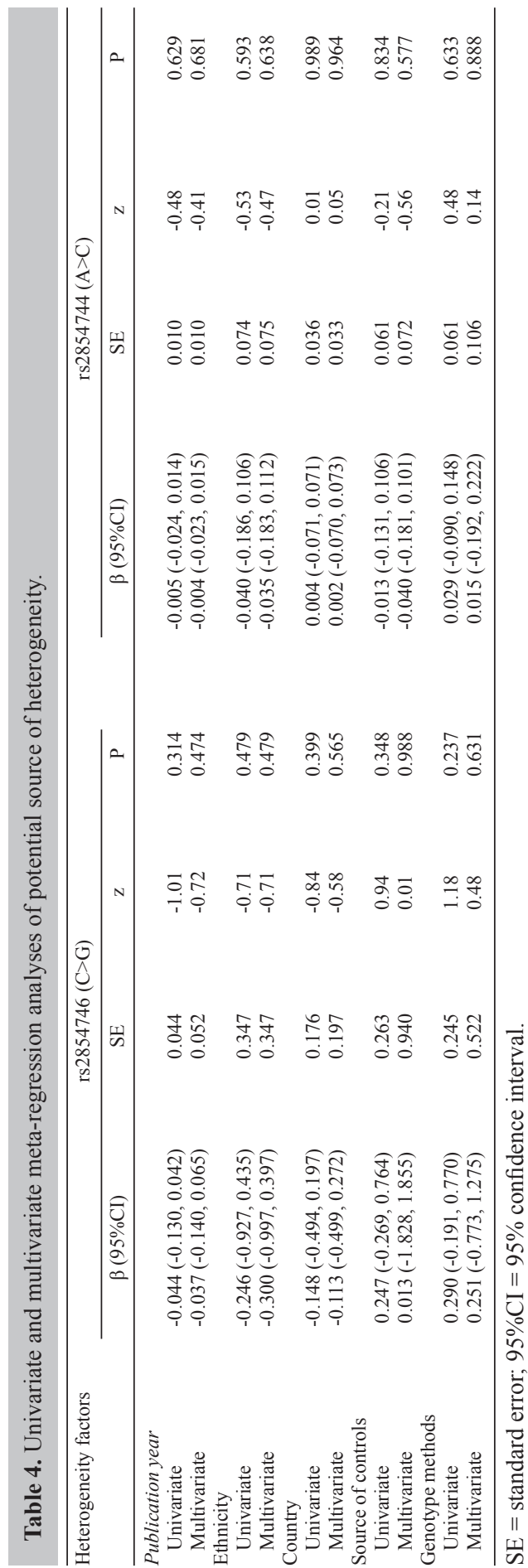




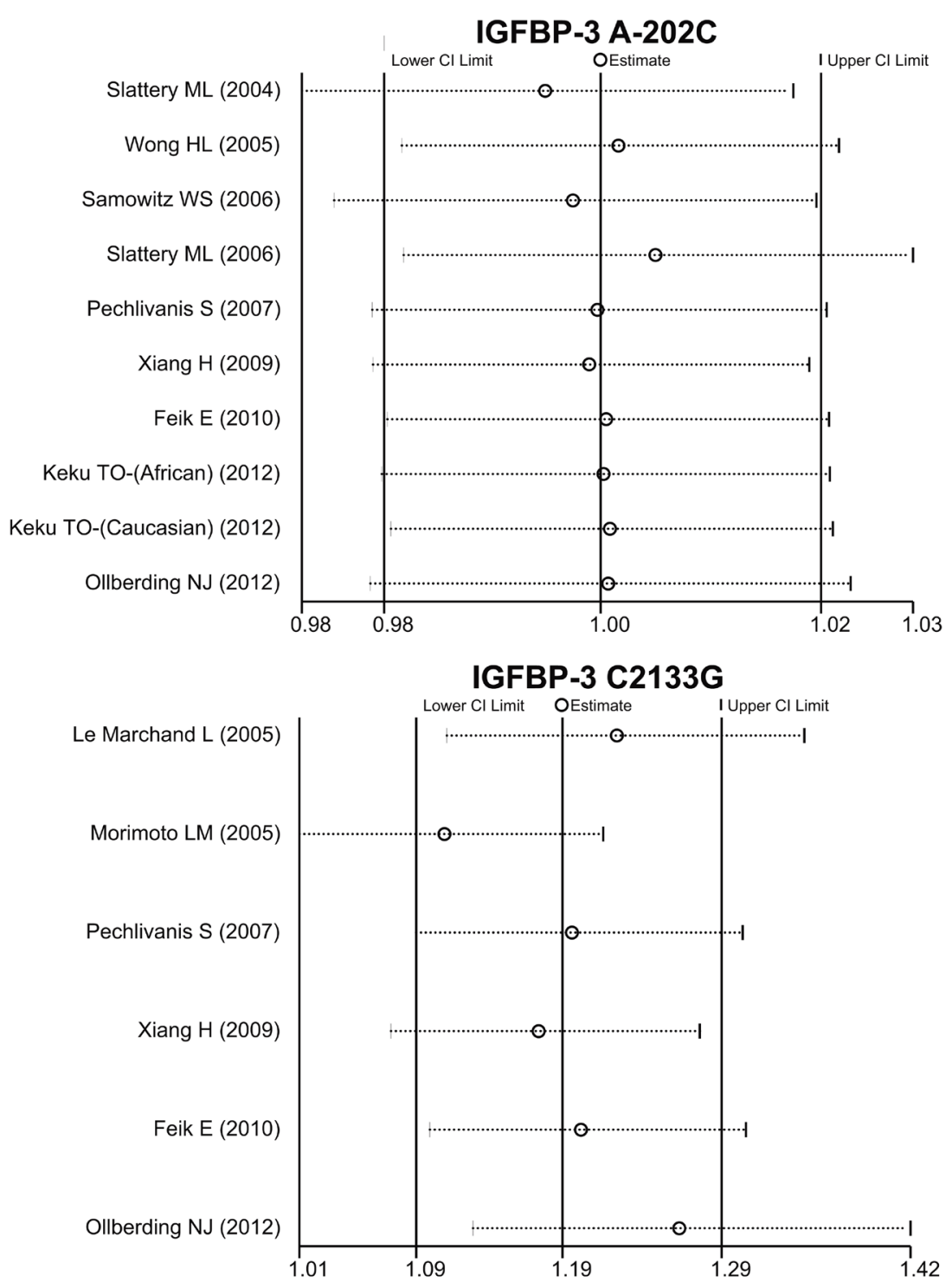

Figure 5. Sensitivity analysis for the associations between IGFBP-3 A-202C and C2133G polymorphisms and colorectal cancer risk under the dominant model. Results were computed by omitting each study in turn. Meta-analysis random-effect estimates (exponential form) were used. The two ends of the dotted lines represent the $95 \% \mathrm{CI}$.

\section{Publication bias evaluation}

Funnel plots and the Egger linear regression test were performed to assess the publication biases of the included studies. The shapes of the funnel plots did not reveal any evidence of obvious asymmetry under the dominant model of A-202C and C2133G polymorphisms 
(Figure 6). The Egger test also did not display strong statistical evidence of publication bias (A-202C: $t=0.33, \mathrm{P}=0.747$; C2133G: $t=-0.07, \mathrm{P}=0.946$ ).
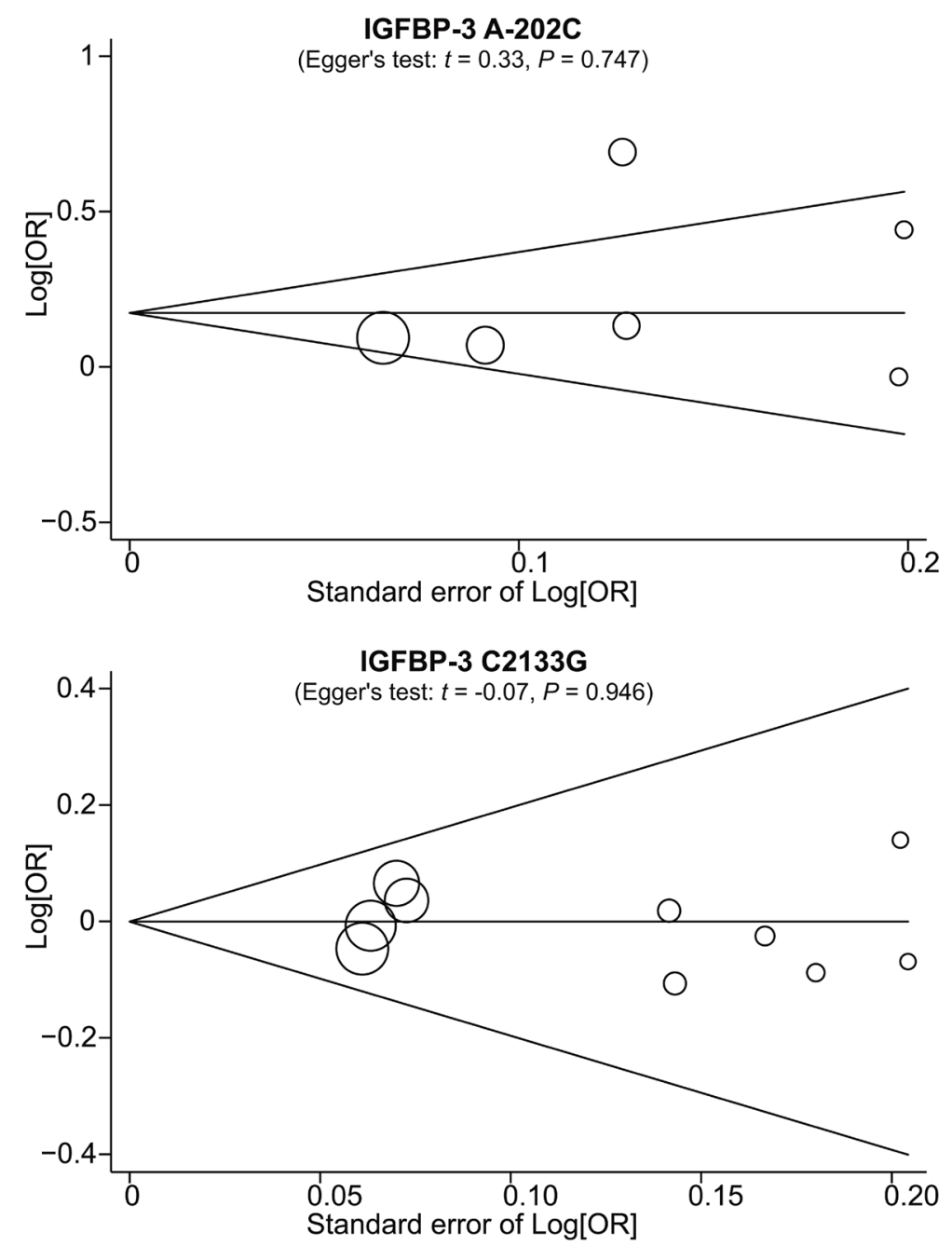

Figure 6. Funnel plots for the associations between IGFBP-3 A-202C and C2133G polymorphisms and colorectal cancer risk under the dominant model. Each point represents a separate study for the indicated association. $\log [\mathrm{OR}]=$ natural logarithm of OR. Horizontal line = mean magnitude of the effect. Note: Funnel plot with pseudo $95 \%$ confidence limits was used.

\section{DISCUSSION}

IGFBP-3, a major serum carrier protein for the IGFs, plays an important role in cancer development (Dokmanovic et al., 2011). Previous studies have demonstrated that IGFBP-3 might reduce cancer risk through its ability to mediate the bioavailability of IGF-1 in circula- 
tion, thereby reducing cellular proliferation and stimulate apoptosis (Ferry et al., 1999; Firth and Baxter, 2002). Several genetic polymorphisms in the IGFBP-3 gene have been identified for predicting the development, progression, and clinical outcomes of colorectal cancer, but A-202C and C2133G were the most common ones (Poole et al., 2012). Many previous genetic studies have suggested that IGFBP A-202C and C2133G polymorphisms play an important role in colorectal carcinogenesis (Le Marchand et al., 2005; Morimoto et al., 2005; Samowitz et al., 2006; Slattery et al., 2006; Xiang et al., 2009; Feik et al., 2010; Keku et al., 2012; Ollberding et al., 2012), while other studies found no convincing evidence of these polymorphisms in increasing the risk of colorectal cancer (Slattery et al., 2004; Wong et al., 2005; Pechlivanis et al., 2007). This controversy could be explained with several reasons, including the differences in study design, sample size, ethnicity, and statistical method. Therefore, this meta-analysis aimed to provide a more comprehensive and reliable conclusion on these associations.

In the present meta-analysis, 11 independent case-control studies were included with a total of 11,895 colorectal cancer patients and 17,147 healthy controls. When all eligible studies were pooled into the meta-analysis, the results showed that the IGFBP C $2133 \mathrm{G}$ polymorphism was associated with an increased risk of colorectal cancer, while a similar association was not observed in the A-202C polymorphism. Although genetic factors that could be responsible for susceptibility to colorectal cancer are well known, the molecular basis is not fully understood. One possible reason for this result could be that the $\mathrm{C} 2133 \mathrm{G}$ polymorphism had a more negative impact than A-202C on the circulating levels of IGF-1 and IGFBP-3, thereby possibly explaining the inter-individual differences in the disease incidence of colorectal cancer. Further subgroup analyses also indicated that the IGFBP C2133G polymorphism might be the main determinants for colorectal cancer risk in the majority of subgroups. These findings are consistent with the previous hypothesis that genetic variations in the IGFBP-3 gene may confer susceptibility to colorectal cancer, suggesting that they may be useful as biomarkers in predicting the genetic susceptibility of an individual to colorectal cancer.

Our meta-analysis has several limitations that should be acknowledged. The first limitation is that the sample size of this meta-analysis was relatively small and may not have sufficient statistical power in estimating the relationships between IGFBP-3 gene polymorphisms and colorectal cancer risk. Therefore, further studies with a larger sample size are still needed. On the other hand, a meta-analysis is a type of a retrospective study and may encounter recall or selection bias, thereby possibly influencing the reliability of our results (Stroup et al., 2000). Most important of all, lack of access to the original study data limited further evaluation of the potential value of these polymorphisms in the IGFBP-3 gene.

In conclusion, our meta-analysis indicates that the IGFBP-3 C2133G polymorphism may confer susceptibility to colorectal cancer. The $\mathrm{G}$ variant of $\mathrm{C} 2133 \mathrm{G}$ polymorphism may serve as a useful biomarker for predicting the risk of colorectal cancer. However, further studies are still needed to accurately determine whether the IGFBP-3 A-202C polymorphism is associated with colorectal cancer risk. Based on the limitations mentioned before, detailed studies are needed to confirm our findings.

\section{ACKNOWLEDGMENTS}

We thank all our colleagues working in the Department of Cardiothoracic Surgery, Second Affiliated Hospital, Wenzhou Medical College. 


\section{REFERENCES}

Chan AT and Giovannucci EL (2010). Primary prevention of colorectal cancer. Gastroenterology 138: 2029-2043.

Costalonga EF, Antonini SR, Guerra-Junior G, Mendonca BB, et al. (2009). The -202 A allele of insulin-like growth factor binding protein-3 (IGFBP3) promoter polymorphism is associated with higher IGFBP-3 serum levels and better growth response to growth hormone treatment in patients with severe growth hormone deficiency. J. Clin. Endocrinol. Metab. 94: 588-595.

de la Chapelle A (2004). Genetic predisposition to colorectal cancer. Nat. Rev. Cancer 4: 769-780.

Dokmanovic M, Shen Y, Bonacci TM, Hirsch DS, et al. (2011). Trastuzumab regulates IGFBP-2 and IGFBP-3 to mediate growth inhibition: implications for the development of predictive biomarkers for trastuzumab resistance. Mol. Cancer Ther. 10: 917-928.

Feik E, Baierl A, Hieger B, Fuhrlinger G, et al. (2010). Association of IGF1 and IGFBP3 polymorphisms with colorectal polyps and colorectal cancer risk. Cancer Causes Control 21: 91-97.

Ferry RJ Jr, Katz LE, Grimberg A, Cohen P, et al. (1999). Cellular actions of insulin-like growth factor binding proteins. Horm. Metab. Res. 31: 192-202.

Firth SM and Baxter RC (2002). Cellular actions of the insulin-like growth factor binding proteins. Endocr. Rev. 23: 824-854.

Furstenberger G and Senn HJ (2002). Insulin-like growth factors and cancer. Lancet Oncol. 3: 298-302.

Giovannucci E (2001). Insulin, insulin-like growth factors and colon cancer: a review of the evidence. J. Nutr. 131: 3109S-3120S.

Ioannidis JP, Patsopoulos NA and Rothstein HR (2008). Reasons or excuses for avoiding meta-analysis in forest plots. BMJ 336: 1413-1415.

Jackson D, White IR and Riley RD (2012). Quantifying the impact of between-study heterogeneity in multivariate metaanalyses. Stat. Med. 31: 3805-3820.

Jemal A, Bray F, Center MM, Ferlay J, et al. (2011). Global cancer statistics. CA Cancer J. Clin. 61: 69-90.

Kaplan RC, Petersen AK, Chen MH, Teumer A, et al. (2011). A genome-wide association study identifies novel loci associated with circulating IGF-I and IGFBP-3. Hum. Mol. Genet. 20: 1241-1251.

Keku TO, Vidal A, Oliver S, Hoyo C, et al. (2012). Genetic variants in IGF-I, IGF-II, IGFBP-3, and adiponectin genes and colon cancer risk in African Americans and Whites. Cancer Causes Control 23: 1127-1138.

Kim WY, Kim MJ, Moon H, Yuan P, et al. (2011). Differential impacts of insulin-like growth factor-binding protein-3 (IGFBP-3) in epithelial IGF-induced lung cancer development. Endocrinology 152: 2164-2173.

Le Marchand L, Kolonel LN, Henderson BE and Wilkens LR (2005). Association of an exon 1 polymorphism in the IGFBP3 gene with circulating IGFBP-3 levels and colorectal cancer risk: the multiethnic cohort study. Cancer Epidemiol. Biomarkers Prev. 14: 1319-1321.

Little J, Higgins JP, Ioannidis JP, Moher D, et al. (2009). STrengthening the REporting of Genetic Association Studies (STREGA) - an extension of the STROBE statement. Genet. Epidemiol. 33: 581-598.

Markowitz SD and Bertagnolli MM (2009). Molecular origins of cancer: Molecular basis of colorectal cancer. N. Engl. J. Med. 361: 2449-2460.

Morimoto LM, Newcomb PA, White E, Bigler J, et al. (2005). Insulin-like growth factor polymorphisms and colorectal cancer risk. Cancer Epidemiol. Biomarkers Prev. 14: 1204-1211.

Ollberding NJ, Cheng I, Wilkens LR, Henderson BE, et al. (2012). Genetic variants, prediagnostic circulating levels of insulin-like growth factors, insulin, and glucose and the risk of colorectal cancer: the Multiethnic Cohort study. Cancer Epidemiol. Biomarkers Prev. 21: 810-820.

Pechlivanis S, Wagner K, Chang-Claude J, Hoffmeister M, et al. (2007). Polymorphisms in the insulin like growth factor 1 and IGF binding protein 3 genes and risk of colorectal cancer. Cancer Detect. Prev. 31: 408-416.

Peters JL, Sutton AJ, Jones DR, Abrams KR, et al. (2006). Comparison of two methods to detect publication bias in metaanalysis. JAMA 295: 676-680.

Poole EM, Tworoger SS, Hankinson SE and Baer HJ (2012). Genetic variability in IGF-1 and IGFBP-3 and body size in early life. BMC Public Health 12: 659.

Ren Z, Cai Q, Shu XO, Cai H, et al. (2004). Genetic polymorphisms in the IGFBP3 gene: association with breast cancer risk and blood IGFBP-3 protein levels among Chinese women. Cancer Epidemiol. Biomarkers Prev. 13: 1290-1295.

Samowitz WS, Wolff RK, Ma KN, Andersen K, et al. (2006). Polymorphisms in insulin-related genes predispose to specific KRAS2 and TP53 mutations in colon cancer. Mutat. Res. 595: 117-124.

Slattery ML, Samowitz W, Curtin K, Ma KN, et al. (2004). Associations among IRS1, IRS2, IGF1, and IGFBP3 genetic polymorphisms and colorectal cancer. Cancer Epidemiol. Biomarkers Prev. 13: 1206-1214.

Genetics and Molecular Research 14 (2): 3370-3386 (2015) 
Slattery ML, Curtin K, Wolff R, Ma KN, et al. (2006). PPARgamma and colon and rectal cancer: associations with specific tumor mutations, aspirin, ibuprofen and insulin-related genes (United States). Cancer Causes Control 17: 239-249.

Stroup DF, Berlin JA, Morton SC, Olkin I, et al. (2000). Meta-analysis of observational studies in epidemiology: a proposal for reporting. Meta-analysis Of Observational Studies in Epidemiology (MOOSE) group. JAMA 283: 2008-2012.

Wong HL, Delellis K, Probst-Hensch N, Koh WP, et al. (2005). A new single nucleotide polymorphism in the insulin-like growth factor I regulatory region associates with colorectal cancer risk in Singapore Chinese. Cancer Epidemiol. Biomarkers Prev. 14: 144-151.

Xiang H, Liu L, Chu GD, Wei S, et al. (2009). Association between two functional polymorphisms of insulin-like growth factor binding protein 3 and colorectal cancer risk in a Chinese population. J. Toxicol. Environ. Health A 72: 706-711.

Zintzaras E and Ioannidis JP (2005). HEGESMA: genome search meta-analysis and heterogeneity testing. Bioinformatics 21: 3672-3673. 